\title{
Distinguishing Anxiety Subtypes of English Language Learners Towards Augmented Emotional Clarity
}

\author{
Heera Lee $\left.{ }^{(}\right)$, Varun Mandalapu, Andrea Kleinsmith, and Jiaqi Gong ${ }^{(\bowtie)}$ \\ University of Maryland, Baltimore County, Baltimore, MD 21250, USA \\ $\{$ heera1, jgong\} @umbc . edu
}

\begin{abstract}
Public Speaking Anxiety (PSA) and Foreign Language Anxiety (FLA) afflict most English Language Learners (ELLs) during a presentation. However, few tools are available to help multicultural learners clearly identify which type of anxiety they are feeling. In this paper, we present a field study conducted in real language classrooms. We developed machine learning models based on features of electrodermal activity (EDA) to predict non-verbal behaviors manifested as PSA and FLA. The students were labeled with the anxiety categories both PSA and FLA, PSA more, FLA more, or no anxiety. To classify the ELLs into their respective anxiety categories, prominent EDA features were employed that supported the predictions of anxiety sources. These results may encourage both ELLs and instructors to be aware of the origins of anxiety subtypes and develop a customized practice for public speaking in a foreign language.
\end{abstract}

Keywords: EDA Features $\cdot$ Speaking anxiety $\cdot$ Emotional clarity

\section{Introduction}

English Language Learners (ELLs) reported more anxiety over speaking than other language skills including reading, writing, or listening $[9,14]$ because Public Speaking Anxiety (PSA) known as social anxiety (e.g., being afraid of audience' attention) [17] and Foreign Language Anxiety (FLA) (e.g., fear of making mistakes in using a foreign language) $[1,8,11]$ are accompanied particularly during presentation performance. Even though ELLs struggle with these subtypes of speaking anxieties, many studies and educators focus on external properties in training $[4,6,12,15]$ rather than careful examination of discrete anxieties $[2,7]$ influencing performance. To improve performance, the ELLs need emotional clarity, which refers to abilities to identify the origins of emotions [3]. By clearly identifying and distinguishing speaking anxieties as the first step, they can determine emotional regulation strategies such as adapting to changing conditions to cope with it [16]. In this context, this study noted the potential to use physiological arousal of electrodermal activity (EDA), which is often considered 
as a biomarker to measure individual anxiety levels, $[5,13]$ in a way to support augmented emotional clarity of ELLs. The main research question of this study is "Can EDA features extracted from wearable sensors classify the main source of speaking anxiety (PSA and FLA) among English language learners during an oral presentation in English?"

\section{Method}

33 students (16 males, 17 female) with intermediate English proficiency were recruited from Speaking classes in the English Language Institute (ELI) at the University of Maryland, Baltimore County (UMBC). The participants were ranged in age from 19 to 43 (mean age \pm 5.67 years). The experimental protocol was approved by the university's Institutional Review Board. The investigators took the presentation task from the ELI instructors to have an authentic experimental setting. To elicit a natural performance from participants, the location of an audio-video recording device was offset slightly to make the presenters less conscious of the camera and being recorded.

\section{Analysis}

As shown in Fig. 1 (a), we developed a framework of four sources of anxiety based on manual behavioral annotations of 33 audio-video recordings: eye contact linked to PSA more $(\mathrm{P})$ as a social anxiety, the number of pauses and filler words (i.e. "um" and "ah") linked to FLA more (F), Both anxieties (B), and No $\operatorname{anxiety}(\mathrm{N})$.

(a)

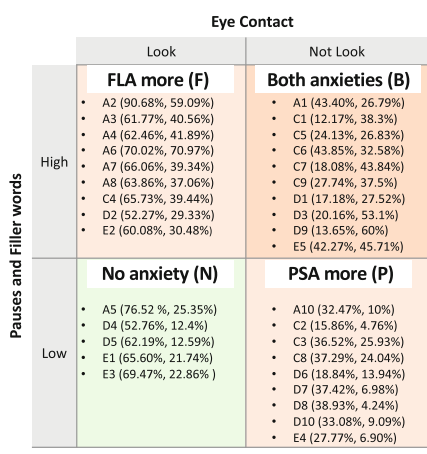

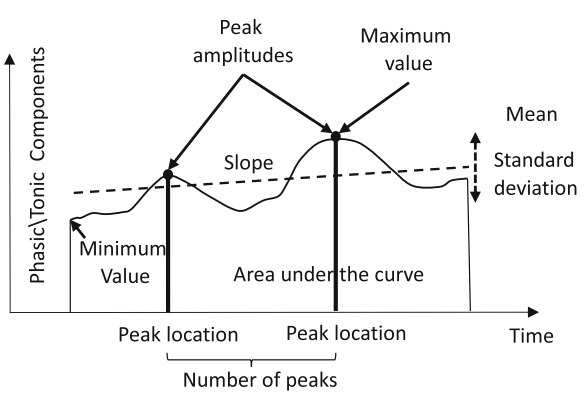

(b)

Fig. 1. (a) Four anxiety framework referring to behavioral annotation data as: participant ID (ratio of eye contact (\%), the number of pauses and filler words (\%)). (b) Ten features of each phasic and tonic from EDA signal

The students were divided into two groups named Look (low PSA) and Not Look (high PSA) based on a $50 \%$ ratio of eye contact with the audience in the 
annotation. These two groups were divided into two subgroups again based on accumulated behavioral annotation on the number of pauses and filler words. These groups were labeled High pauses and filler words (high FLA) and Low pauses and filler words (low FLA). The reference percentage of dividing these coordinates was the $25 \%$, which corresponded with the interviewees' statements.

The EDA data collected from 33 participants underwent multiple cleaning and feature extraction steps. To reduce the severity of artifacts in EDA data, we used a smoothing method based on Hann function with a window size of $1 \mathrm{~s}$. Once we removed artifacts in the EDA signal data, we used a range normalization function to normalize EDA data of all participants to mitigate the individual EDA signal differences between subjects and reduce bias. Once the data was cleaned, we extracted two sets of features from the EDA data. One set consisted of phasic and tonic components of one-dimensional EDA data, and the other set consisted of time-frequency (TF) and energy distribution extracted based on Hilbert Huang Transformation (HHT) method. The phasic and tonic features were further processed to extract mean, standard deviation, minimum and maximum values in a component, locations of minimum and maximum values, mean peak amplitudes, number of peaks, slope, and area under the curve as shown in Figure 1 (b). These EDA features were extracted based on a sliding window of $10 \mathrm{~s}$ with an overlap of five seconds that translates to 5326 windows. Similar to the phasic and tonic features, the TF features were extracted based on the same sliding window method.

\subsection{Model Development}

To understand the importance of different EDA features on ELL anxiety classification, we divide the datasets into multiple subsets based on features and labels. One subset of data consists of all features from Tonic and Phasic components of EDA signal, and time-frequency features from HHT. The other subsets include either tonic-phasic or HHT features. To classify ELL into one of the four anxieties framework,we adopted five machine learning algorithms: Decision Tree, Auto Multilayer Perceptron, Gradient Boosted Tree, Random Forest and Support Vector Machine. All the models are validated using a 10-fold crossvalidation method that uses nine subsets of data for training and one for testing, and then it iterates until the algorithm predicts for all samples in a dataset. All the classification algorithms in this study are developed in the RapidMiner data science platform [10]. This study also focuses on identifying features that play a significant role in model prediction using LIME based feature importance method.

\section{Result}

The performance of each classifier is evaluated based on four metrics: Accuracy, Cohens Kappa, Recall, and Precision. Based on the comparison of these performance metrics between different classifiers on multiple datasets, gradient 
boosting algorithm outperformed other classifiers as shown in Table 1. Furthermore, we also developed binary classifiers to classify 18 ELLs with 2622 samples that belong to either PSA or FLA anxiety types. GBT classifier performed well in predicting ELL anxiety type based on different input feature sets. Table 1 shows that the performance of GBT classifier with all features (HHT + PhasicTonic) is the highest. Finally, we also extract the feature importance of both multiclass and binary class GBT model predictions with varying inputs based on a LIME method mentioned in the earlier section. The Table 2 shows the top three supporting features of each classifier.

Table 1. The performance of multi-class and binary class gradient boosting classifier on different feature inputs.

\begin{tabular}{c|c|c|c|c|c|c|c|c}
\hline $\begin{array}{c}\text { Input } \\
\text { Features }\end{array}$ & \multicolumn{2}{|c|}{ Accuracy } & \multicolumn{2}{c|}{ Kappa } & \multicolumn{2}{c|}{ Recall } & \multicolumn{2}{c}{ Precision } \\
\hline $\begin{array}{c}\text { Class } \\
\text { PhasicTonic } \\
\text { HHT }\end{array}$ & Multi & Binary & Multi & Binary & Multi & Binary & Multi & Binary \\
\hline PhasicTonic & 75.76 & 100.00 & 0.45 & 1.00 & 61.67 & 100.00 & 85.87 & 100.00 \\
\hline HHT & 57.78 & 88.89 & 0.41 & 0.78 & 54.55 & 88.89 & 60.42 & 90.91 \\
\hline
\end{tabular}

Table 2. Top three supporting features of a GBT algorithm on different data subsets based on a LIME method

\begin{tabular}{|c|c|c|c|c|c|c|}
\hline $\begin{array}{c}\text { Class_ } \\
\text { Support } \\
\text { Attribute }\end{array}$ & $\begin{array}{c}\text { Multi_ } \\
\text { Phasic } \\
\text { Tonic } \\
\text { HHT }\end{array}$ & $\begin{array}{c}\text { Binary- } \\
\text { Phasic } \\
\text { Tonic } \\
\text { HHT }\end{array}$ & $\begin{array}{l}\text { Multi_- } \\
\text { Phasic } \\
\text { Tonic }\end{array}$ & $\begin{array}{c}\text { Binary_- } \\
\text { Phasic } \\
\text { Tonic }\end{array}$ & $\begin{array}{c}\text { Multi_ } \\
\text { HHT }\end{array}$ & $\begin{array}{c}\text { Binary - } \\
\text { HHT }\end{array}$ \\
\hline 1 & $\begin{array}{c}\text { HHT } \\
\text { Feature } \\
(0-0.1 \mathrm{~Hz})\end{array}$ & $\begin{array}{c}\text { HHT } \\
\text { Feature } \\
(0-0.1 \mathrm{~Hz})\end{array}$ & $\begin{array}{c}\text { Min.Tonic } \\
\text { component } \\
\text { value }\end{array}$ & $\begin{array}{l}\text { Sd. of } \\
\text { Tonic } \\
\text { data }\end{array}$ & $\begin{array}{c}\text { HHT } \\
\text { Feature } \\
(0-0.1 \mathrm{~Hz})\end{array}$ & $\begin{array}{c}\text { HHT } \\
\text { Feature } \\
(0-0.1 \mathrm{~Hz})\end{array}$ \\
\hline 2 & $\begin{array}{c}\text { Min. Tonic } \\
\text { component } \\
\text { value }\end{array}$ & $\begin{array}{c}\text { Slope of } \\
\text { Tonic } \\
\text { data }\end{array}$ & $\begin{array}{c}\text { Min. Phasic } \\
\text { component } \\
\text { value }\end{array}$ & $\begin{array}{l}\text { Sd. of } \\
\text { Phasic } \\
\text { data }\end{array}$ & $\begin{array}{c}\text { HHT } \\
\text { Feature } \\
(1.8-1.9 \mathrm{~Hz})\end{array}$ & $\begin{array}{c}\text { HHT } \\
\text { Feature } \\
(1.8-1.9 \mathrm{~Hz})\end{array}$ \\
\hline 3 & $\begin{array}{c}\text { Max. Phasic } \\
\text { component } \\
\text { value }\end{array}$ & $\begin{array}{c}\text { Sd. of } \\
\text { Phasic } \\
\text { data }\end{array}$ & $\begin{array}{c}\text { Max. Phasic } \\
\text { component } \\
\text { value }\end{array}$ & $\begin{array}{c}\text { Max. Phasic } \\
\text { component } \\
\text { value }\end{array}$ & $\begin{array}{c}\text { HHT } \\
\text { Feature } \\
(1.5-1.6 \mathrm{~Hz})\end{array}$ & $\begin{array}{c}\text { HHT } \\
\text { Feature } \\
(1.5-1.6 \mathrm{~Hz})\end{array}$ \\
\hline
\end{tabular}

\section{Conclusion and Future Work}

Our findings demonstrate the potential in using EDA to develop a classification model to identify subtypes of speaking anxiety (PSA and FLA). Our future work will focus on developing and evaluating an interactive education system where ELLs can identify their predominant speaking anxiety and apply it to emotional regulation strategies to cope with their anxiety. 


\section{References}

1. Al-Nouh, N.A., Abdul-Kareem, M.M., Taqi, H.A.: EFL college students' perceptions of the difficulties in oral presentation as a form of assessment. Int. J. Higher Educ. 4(1), 136-150 (2015)

2. Bosch, N., et al.: Automatic detection of learning-centered affective states in the wild. In: Proceedings of the 20th International Conference on Intelligent User Interfaces, pp. 379-388 (2015)

3. Butler, R.M., et al.: Emotional clarity and attention to emotions in cognitive behavioral group therapy and mindfulness-based stress reduction for social anxiety disorder. J. Anxiety Disorders 55, 31-38 (2018)

4. Chen, L., Feng, G., Joe, J., Leong, C.W., Kitchen, C., Lee, C.M.: Towards automated assessment of public speaking skills using multimodal cues. In: Proceedings of the 16th International Conference on Multimodal Interaction, pp. 200-203. ACM (2014)

5. Croft, R.J., Gonsalvez, C.J., Gander, J., Lechem, L., Barry, R.J.: Differential relations between heart rate and skin conductance, and public speaking anxiety. J. Behav. Therapy Experimental Psychiatry 35(3), 259-271 (2004)

6. Damian, I., Tan, C.S.S., Baur, T., Schöning, J., Luyten, K., André, E.: Augmenting social interactions: realtime behavioural feedback using social signal processing techniques. In: Proceedings of the 33rd Annual ACM Conference on Human Factors in Computing Systems, pp. 565-574. ACM (2015)

7. Dixon, L.Q., et al.: What we know about second language acquisition: a synthesis from four perspectives. Rev. Educ. Res. 82(1), 5-60 (2012)

8. Epp, C.D.: English language learner experiences of formal and informal learning environments. In: Proceedings of the Sixth International Conference on Learning Analytics \& Knowledge, pp. 231-235 (2016)

9. Horwitz, E.K., Horwitz, M.B., Cope, J.: Foreign language classroom anxiety. Modern Language J. 70(2), 125-132 (1986)

10. Mierswa, I., Klinkenberg, R.: Rapidminer studio (2019)

11. Radzuan, N.R.M., Kaur, S.: Technical oral presentations in english: qualitative analysis of malaysian engineering undergraduates' sources of anxiety. ProcediaSoc. Behav. Sci. 29, 1436-1445 (2011)

12. Schneider, J., Börner, D., Van Rosmalen, P., Specht, M.: Presentation trainer, your public speaking multimodal coach. In: Proceedings of the 2015 ACM on International Conference on Multimodal Interaction, pp. 539-546. ACM (2015)

13. Sevinç, Y.: Language anxiety in the immigrant context: sweaty palms? Int. J. Bilingualism 22(6), 717-739 (2018)

14. Swain, M.: The inseparability of cognition and emotion in second language learning. Language Teach. 46(2), 195-207 (2013)

15. Tanveer, M.I., Zhao, R., Chen, K., Tiet, Z., Hoque, M.E.: Automanner: an automated interface for making public speakers aware of their mannerisms. In: Proceedings of the 21st International Conference on Intelligent User Interfaces, pp. 385-396. ACM (2016)

16. Thompson, R.A.: Emotion regulation: a theme in search of definition. Monographs Soc. Res. Child Dev. 59(2-3), 25-52 (1994)

17. Young, D.J.: An investigation of students' perspectives on anxiety and speaking. Foreign Language Ann. 23(6), 539-553 (1990) 